\title{
EDUCAÇÃO DO CAMPO NO TOCANTINS: ANÁLISE SITUACIONAL
}

Field education in Tocantins: Situational analysis

Campo de laeducaciónen Tocantins: Análisis de lasituación

\section{Kellyane Dias Prado ${ }^{* 1}$, Idemar Vizolli ${ }^{1}$, Darlene Araújo Gomesr ${ }^{1}$}

${ }^{1}$ Curso de Pedagogia, Campus de Arraias, Universidade Federal do Tocantins, Arraias, Tocantins, Brasil.

*Correspondência: Avenida Juraildes de Sena Abreu, s/n - Sentor Buritizinho, Arraias - TO, 77330-000. E-mail: kellyaneprado@hotmail.com

\section{RESUMO}

A Educação do Campo no Estado do Tocantins tem sido objeto de estudos no meio acadêmico e fomentado o desenvolvimento de pesquisas. Este artigo é parte de um estudo mais amplo que visa compreender a realidade da educação ofertada aos campesinos do Estado do Tocantins e tem como objetivo analisar a realidade das escolas localizadas no meio rural na região de abrangência da $13^{\mathrm{a}}$ Diretoria Regional de Ensino, localizada em Arraias, TO. Inspirados na pesquisa qualitativa buscou-se nos bancos de dados do MEC, IBGE, INEP, Secretarias Estadual e Municipais de Educação do Estado do Tocantins, informações acerca da realidade das escolas, com destaque ao quantitativo de matrículas. Os resultados indicam que a população rural do Tocantins é bastante significativa, vinculando o número de alunos matriculados ao processo de nucleação das escolas, fazendo com que os estudantes do meio rural migrem para o meio urbano, o que nos remete à transposição do modelo urbano, não atendendo ao que preconiza as Diretrizes Operacionais para a Educação Básica nas Escolas do Campo.

Palavras-chave: Educação do Campo. Políticas Públicas. Diretrizes Operacionais.

\section{ABSTRACT}

Field Education in the State of Tocantins has been the subject of studies in the academic field and has encouraged the development of research. This article is part of a broader study aimed at understanding the reality of the education offered to farmers in the state of Tocantins and aims to analyze the reality of schools located in rural areas in the region covered by the 13th Regional Education Board located in Arraias, TO. Inspired by the qualitative research, information about the reality of schools was sought in the databases of the MEC, IBGE, INEP, State and Municipal Departments of Education of the State of Tocantins, with emphasis on the number of enrollments. The results indicate that the rural population of Tocantins is quite significant, linking the number of students enrolled in the process of nucleation of schools, causing the rural students to migrate to the urban environment, which refers to the transposition of the urban model, Not taking into account what is recommended in the Operational Guidelines for Basic Education in the Field Schools.

Keywords: Field Education. Public policy. Operational Guidelines.

\section{RESUMEN}

La Educación Rural en el Estado de Tocantins se ha estudiado en la academia y fomentado el desarrollo de la investigación. Este artículo es parte de un estudio más amplio para comprender la realidad de la educación que se ofrece en el estado de Tocantins campesinos y tiene como objetivo analizar la realidad de las escuelas ubicadas en zonas rurales de la región que abarca el 13 Junta Regional de Educación, situada en Arraias, A. Inspirado por la investigación cualitativa se buscó en las bases de datos del MEC, el IBGE, INEP, Estatal y Municipal del Estado de Tocantins Educación, la información sobre la realidad de las escuelas, especialmente la matrícula cuantitativa. Los resultados indican que la población rural Tocantins es bastante significativo, que une el número de alumnos matriculados en el proceso de nucleación de las escuelas, por lo que los estudiantes de zonas rurales emigran a las zonas urbanas, lo que nos lleva a la transposición del modelo urbano, no responder a las llamadas que las Directrices operativas para la educación básica en las escuelas rurales.

Descriptores:Educación Rural. Políticas públicas. Directrices operacionales. 


\section{INTRODUÇÃO}

Nos últimos anos, com a entrada de professores e acadêmicos na Universidade Federal do Tocantins engajados em pesquisas sobre a educação dos povos que vivem no e do campo, nos levou a questionar acerca da realidade da educação ofertada a esta população, o que suscitou essa pesquisa.

Diante disso sabemos que o campo enquanto espaço de existência humana, traz a ligação dos seres humanos com a produção das condições da sua existência social, neste contexto, a escola possui papel fundamental na produção dessa existência. Portanto coadunamos com Caldart (2007) quando ela afirma que o campo só pode ser "compreendido/discutido no contexto de seu surgimento: a sociedade brasileira atual e a dinâmica específica que envolve os sujeitos sociais do campo" (CALDART, 2007 p.2-3)

Diante disso, pensar a educação do campo é pensar em estratégias que ajudem a reafirmar identidades do campo, contrapor aos conceitos e definições e às políticas de educação rural, que configuram o pensamento liberal/neoliberal, presentes na história da educação brasileira. Fernandes (2004 apud GOMES, 2015), afirma que o campo não é só lugar da produção agropecuária e agroindústria, do latifúndio e da grilagem de terras, mas o campo é espaço e território dos camponeses e quilombolas e por tudo isso, campo é lugar de vida e, sobretudo de educação.

A Educação do Campo em sua especificidade foi conquistada após muitas lutas dos movimentos sociais do campo como o MST, Comissão Pastoral da Terra e muitos outros, que juntos buscavam um reconhecimento por parte da diversidade do campo estão conseguindo aos poucos um maior reconhecimento das necessidades do campo, e que resultaram nas proposições instituídas nas Diretrizes Operacionais para a Educação Básica do Campo (BRASIL, 2002).

Neste sentido, busca-se uma educação que valorize as especificidades dos camponeses, dos saberes, dos espaços e tempos de aprendizagem atendendo todas as suas peculiaridades, bem como uma pedagogia diferenciada que possa atender as exigências do campo além de garantir a permanencia do camponês no campo respeitando sua cultura,além de preparar este camponês para a modernidade, mas sem jamais perder suas características campesinas. (SCHULTZ; LIRA, 2011 ).

O lócus da pesquisa é o Estado do Tocantins, que segundo dados do IBGE/2010 possui uma área demográfica de $277.720,520 \mathrm{~km}^{2}$, densidade demográfica de 4,98hab/km², com 139 municípios; apresenta uma população total de 1.383.445h, dos quais $1.090 .106 \mathrm{~h}$ (79\%) estão na zona urbana e 293.339 h (21\%) na zona rural, contando com um número significativo de escolas e povos do campo que lutam pelos seus territórios educativos e pelo direito a educação.

\section{MATERIAIS E MÉTODOS}

Esta pesquisa foi desenvolvida em três etapas. Na primeira realizamos estudos bibliográficos sobre a temática "Educação do Campo", que possibilitaram o aprofundamento do conhecimento acerca do assunto, e também sobre as questões agrárias e a pedagogia da alternância, envolvendo os participantes do Grupo de Estudos e Pesquisas sobre Educação do Campo (GEPEC) do campus de Arraias/TO, cujas leituras permitiram discutir a relação terra/homem/trabalho/educação.

Em meio às muitas leituras realizadas demos ênfase ao artigo intitulado "Cenário da Educação do campo no Estado do Tocantins", de Nunes (2013), no qual a pesquisadora afirma que o Tocantins é um 
território movido pela grande produção da agroindústria, onde o capitalismo consegue impor ao mundo rural a cultura urbana, o que repercute na identidade cultural dos campesinos, na exclusão social e no aumento das desigualdades de oportunidades na oferta de uma educação de qualidade.

Buscamos nos bancos de dados do MEC, IBGE, INEP, Secretarias Estadual e Municipais de Educação do Estado do Tocantins, informações acerca do quantitativo de estudantes matriculados, calendário escolar, formação dos professores que atuam em escolas localizadas no meio urbano e rural e também as peculiaridades sociais, políticas e econômicas das localidades em que as escolas estão inseridas.

A abordagem da pesquisa inspira-se na análise qualitativa, especialmente porque analisamos a realidade da "Educação do Campo" no Estado do Tocantins. Para Minayo (1994), a abordagem qualitativa consegue respondera questões particulares e trabalhar com um universo de significados, motivos, aspirações, crenças, valores e atitudes de indivíduos ou comunidades, correspondendo a uma análise mais aprofundada, tanto das relações como dos processos e fenômenos que não podem ser reduzidos apenas a operacionalização de variáveis.

A fim de conhecer a realidade dos povos do campo realizamos um levantamento de dados na Diretoria Regional de Ensino na cidade de Arraias, onde foi possível constatar que existem programas do Governo Federal que atendem as comunidades rurais da região de Arraias, TO, tais como: o programa Direito de Aprender, Programa Ensino Médio Inovador e Mais Educação. Em relação às políticas públicas, chegou-se à conclusão de que nosso olhar deveria direcionar-se para além da educação básica, percorrendo também o processo de implantação da Licenciatura em Educação do Campo em nível superior, na Universidade Federal do Tocantins (UFT), no campus de Arraias.

$\mathrm{O}$ terceiro momento da nossa pesquisa constituiu-se na apresentação dos resultados e discussões da pesquisa, no qual buscamos dialogar com os autores estudados, durante a execução do projeto.

\section{RESULTADOS E DISCUSSÃO}

A educação no âmbito do Estado de direito pode ser considerada uma ação estratégica para a emancipação das pessoas que vivem e trabalham no campo, podendo colaborar com a formação desses sujeitos e para o desenvolvimento sustentável regional e nacional.

No interior do debate sobre a identidade escolar rural, Fernandes e Molina (2004), afirmam que a Educação do Campo é um novo paradigma que rompe com o padrão da Educação Rural, que tem como referência ao campo somente como lugar da produção de mercadorias e não como espaço de vida.

Para Souza (2008), embora a concepção de educação do campo venha se fortalecendo nos últimos anos, vale destacar que a situação pedagógica e de infraestrutura nas escolas públicas ainda é bastante precária. "Por um lado, em muitos estados as escolas passaram por um processo de nucleação política municipal e/ou estadual de fechamento de escolas e abertura ou fortalecimento de escolas localizadas numa área central, entre bairros ou vilas rurais" (SOUZA, 2008, p.1098).

Segundo o Censo 2013 (MEC/INEP), o Estado do Tocantins possui um total de 5.360 escolas públicas (municipais e estaduais) de Educação Básica, destas, 284estão localizadas no meio rural. Os maiores contingentes de alunos matriculados se encontram na zona urbana. Muitos fatores têm colaborado para esta realidade, dentre eles a nucleação, que se constitui em projeto das Secretarias 
Municipais de Educação o que contribuiu para redução de matrículas e o êxodo rural (GOMES, 2015).

De acordo com Nunes (2013, apud GOMES 2015), algumas das políticas públicas que atendem o campo não são pensadas necessariamente a partir da realidade do campo, mas da realidade urbana, que consideram o campo como sinônimo de atraso em oposição à imagem do urbano, atualmente a ideia de desenvolvimento, progresso e sucesso econômico:

O Estado do Tocantins, com tantas disparidades socioeconômicas e culturais internas e até em relação a outras regiões, enfrenta enormes desafios para a educação do campo no Estado, tais como: a qualificação docente para trabalhar com alunos e alunas da área rural com níveis diferentes de escolaridade, e de aprendizagem; o difícil acesso às escolas ou pelas longas distâncias a percorrer ou pela deficiência do transporte escolar, enfim, o desfecho, o êxodo rural dos alunos do campo para acidade (NUNES, 2013, p. 11).

Segundo dados da Secretaria de Educação do Município de Arraias existem 15 escolas rurais espalhadas pelas regiões do Mimoso, Aparecida, Soledade, Poções, Canabrava, Lagoa da Pedra, Jacaré, Salobro, Matas e Canjicas. Algumas dessas escolas ofertam o ensino da educação infantil até $9^{\circ}$ ano do Ensino Fundamental. Muitas delas estão em processo de construção de currículos adequados para os sujeitos do campo, o calendário escolar também está sendo adaptado, para que possa atender as peculiaridades dos sujeitos campesinos (GOMES, 2015).

O número de escolas nos municípios da região do sudeste do Tocantins não é suficiente para atender a população que vive no campo, obrigando crianças e jovens a saírem de seus lares na madrugada e enfrentar estradas precárias e falta de uma alimentação adequada, em busca da educação formal. Contudo, algumas dessas escolas contam com políticas públicas como o Programa Nacional de Educação do Campo (PRONACAMPO), Transporte
Escolar, e programas criados pelo Governo Federal como o Mais Educação e o Programa Dinheiro Direto na Escola (PDDE).

Ressalta-se também, a existência do Programa Nacional de Acesso ao Ensino Técnico e Emprego (PRONATEC), entre outros, que também beneficiam os estudantes do campo possibilitando a instrumentalização para a transformação da realidade local, nos aspectos sociais e econômicos, assim, como a alternativa de permanecer no campo, se assim o desejarem.

De acordo com Nunes (2013), a implementação de políticas públicas para a educação no Tocantins, no regime da colaboração entre os entes Federados, o Estado e o Município não impediu o processo de nucleação o que resultou na desativação das escolas no meio rural, ficando mais fácil e barato, tirar essas crianças e jovens do campo e levá-los para acidade, o que repercute, muitas vezes no abandono escolar desses alunos.

De acordo Mazzini e Oliveira (2010), políticas públicas são instrumentos utilizados pelo estado para a intervenção na realidade rural e urbana que influenciam avida das pessoas. Deste modo, as políticas públicas devem favorecer o fortalecimento do cooperativismo, da organização coletiva, da assistência técnica integral e da extensão rural, além das políticas voltadas para produção e comercialização.

As análises dos dados nos levam a compartilhar com Arroyo (2004), que estamos em um tempo propício para mudanças, onde não se aceita mais políticas públicas compensatórias, mas políticas que respeitem o específico do campo, pois o campo está mudando e encontra-se em movimento.

Ao longo dos anos, a educação no meio rural foi mantida por Igrejas, movimentos sociais e partidos de esquerda. Tendo, os movimentos sociais grande destaque na reivindicação do direito por uma 
Educação do Campo, tendo o Movimento dos Trabalhadores Sem Terra (MST), um papel protagonista nesta luta. Em 03 de abril de 2002, os movimentos sociais se firmam nas reivindicações, com a aprovação das Diretrizes Operacionais para a Educação Básica nas Escolas do Campo e com isso, maior implementação de políticas públicas para o campo, que reconhece no Art. $2^{\circ}$, parágrafo único:

\begin{abstract}
A identidade da escola do campo é definida pela sua vinculação às questões inerentes à sua realidade, ancorando-se na temporalidade $\mathrm{e}$ saberes próprios dos estudantes, na memória coletiva que sinaliza futuros, na rede de ciência e tecnologia disponível na sociedade e nos movimentos sociais em defesa de projetos que associem as soluções exigidas por essas questões à qualidade social da vida coletiva no país (BRASIL, 2002).
\end{abstract}

As Diretrizes constituem um importante marco referencial nas políticas públicas e como instrumento norteador na materialidade educacional para a população que vive no e do campo. Reis (2011) afirma que força do parecer das Diretrizes é significativa, na medida em que apresenta como princípio, a defesa de políticas sociais universalistas, rejeitando as de caráter compensatório. Assim, estas remetem à participação qualificada dos professores, alunos, pais, movimentos sociais e setores organizacionais, visando à vinculação da escola às demandas do campo.

As Diretrizes consideram que a universalização da educação escolar se dá através da articulação de experiências e estudos voltados para o mundo do trabalho. Como marco legal norteador das políticas públicas para as escolas do campo, as diretrizes representam uma conquista para a população campesina.

Neste contexto, os movimentos sociais tiveram um papel significativo na proposição de um novo modelo para a escolarização dos povos do campo, que, de acordo Caldart (CALDART, 2007 p.6) deve desafiar o pensamento pedagógico a entender estes processos, econômicos, políticos, culturais, como formadores do ser humano e, portanto, constituintes de um projeto de educação emancipatória, onde quer que ela aconteça inclusive na escola.

Ao realizarmos a pesquisa sobre a situação das escolas do campo na região do município de Arraias, observou-se que há falta de infraestrutura e investimos do município e do Estado nas escolas localizadas na zona rural. Em muitas delas sequer os calendários letivos foram adequados a fim de garantir os tempos escolares condizentes com as especificidades e necessidades dos estudantes.

Nunes (2013, p. 10) denuncia que é "mais fácil reduzir o número de escolas isoladas, ou seja, fechar as escolas e transferir os alunos para outras escolas de preferência mais perto do centro urbano, do que mantê-las, onde estão, é que está acontecendo na maioria dos municípios do Tocantins".

A região sudeste do Tocantins conta com apenas três escolas estaduais localizadas na zona rural e que atendem alunos desde o $1^{\circ}$ ano do ensino fundamental até o $3^{\circ}$ ano do ensino médio: Escola Estadual Zulmira Magalhães localizada no distrito rural de Canabrava, Escola Estadual Floresta, ambas no município de Arraias e a Escola Estadual Santa Ana do Rio Palmas no município de Paranã. Em Aurora, Lavandeira, Novo Alegre e Combinado os estudantes têm que se deslocarem para as escolas localizadas na sede do município. Este deslocamento favorece a perda de identidade dos estudantes na sua relação com o campo.

A esse respeito Barros e Hage (2011, s/p) esclarecem que em muitos casos, "as escolas localizadas nas pequenas comunidades rurais encontram-se muito precarizadas e funcionando em péssimas condições, entretanto, a solução para essa problemática não pode ser somente a extinção dessas escolas e o investimento no deslocamento dos 
estudantes para escolas localizadas em comunidades mais estruturadas ou nas sedes municipais, o que implica dizer que a política de nucleação não deve ser vista como a principal alternativa para a solução dos problemas enfrentados pelas escolas nas pequenas comunidades rurais".

As propostas pedagógicas das escolas localizadas no meio rural do Tocantins, também evidenciam a concepção do urbano sobre o rural. Em observância ao que preconiza nas Diretrizes Operacionais para a Educação do Campo (2002), porém, há um esforço por parte do poder público (representados pela Secretaria Municipal de Educação de Arraias e Secretaria Estadual de Educação do Tocantins), em fomentar cursos de formação continuada para os professores que atuam no campo.

A implantação do Curso de Licenciatura em Educação do Campo, na UFT em Arraias, pode ser considerada uma importante iniciativa ao atendimento das demandas das políticas públicas para a Educação do Campo, na medida em que formação de docentes para atuar na Educação Básica das escolas do campo, repercutirá na qualidade da oferta da educação à população residente no meio rural

\section{CONCLUSÃO}

A educação ofertada aos povos do campo na região pesquisada, ainda configura uma transposição do modelo urbano, não atendendo as proposições das Diretrizes Operacionais para a Educação Básica nas Escolas do Campo.

Esperamos que esta pesquisa possa contribuir para um a melhor compreensão da realidade das escolas do campo localizadas no meio rural na região de abrangência da $13^{a}$ Diretoria Regional de Ensino, localizada em Arraias, TO, uma vez que os dados ora apresentados, revelam as condições da oferta educacional para o estudante que vive no e do campo, e desnudam as desvantagens em relação à educação ofertada aos estudantes que residem no meio urbano. Ressaltamos que não pretendemos exaurir as discussões em torno destas constatações, e que as considerações aqui delineadas, são provisórias.

\section{AGRADECIMENTO}

Agradecemos a Universidade Federal do Tocantins e ao CNPq por nos possibilitar realizar esta pesquisa. E ainda aos professores Idemar Vizolli e Darlene Araújo Gomes por me apoiarem nesta caminhada.

Todos os autores declararam não haver qualquer potencial conflito de interesses referente a este artigo.

\section{REFERÊNCIAS}

BRASIL. A Educação do Campo em Foco: Uma Análise Interdisciplinar da Realidade das Escolas Rurais do Sudoeste do Tocantins. Projeto de pesquisa edital038/2010/CAPES/INEP.

Diretrizes Operacionais para a Educação

Básica nas Escolas do campo. Resolução CNE/ CEB N ${ }^{\circ}$ 1, de 3 de Abril de 2002.

MEC/ Instituto Nacional de Estudos e Pesquisas Educacionais Anísio Teixeira. Disponível em http://portal.inep.gov.br/basi

BARROS, Oscar F. HAGE, Salomão, M. Panorama estatístico e aspectos legais das políticas de nucleação e transporte escolar: reflexões sobre a extinção das escolas multisseriadas e sua permanência nas comunidades do campo. I Encontro de pesquisas e práticas em educação do campo na Paraíba - 01 a 03 de Junho de 2011. Disponível emhttp://www.ieppecpb2011.xpg.com.br/conteudo/G Ts/GT \%20-\%2002/21.pdf, acesso em 02 de julho de 2014

CALDART, R.S. Sobre educação do campo- In: III Seminário do Programa Nacional de Educação.

FERNANDES, Bernardo Mançano; MOLINA, Mônica Castagna. O Campo da Educação do Campo. In: MOLINA, Mônica Castagna; JESUS, Sonia Meire Santos Azevedo de. (Orgs.). Por Uma Educação do Campo: contribuições para a construção de um Projeto de Educação do Campo. Brasília: 
Articulação Nacional "Por uma Educação do Campo", 2004.

GOMES, Darlene Araújo. Percursos e desafios da licenciatura em Educação do Campo na UFT. Palmas: PPGE/UFT, 2015 (Dissertação de Mestrado) MINAYO, M.C.S. O desafio do conhecimento científico: pesquisa qualitativa em saúde. $2^{\mathrm{a}}$ Edição. São Paulo: Hucitec-Abrasco, 1994.

MAZZINI, Eliane de Jesus Teixeira; OLIVEIRA, Sônia Maria de. Políticas públicas para o campo: desafios da produção e da organização da agricultura familiar. In: VIII Congresso Latino americano de sociologia rural. Anais... Porto de Galinhas, 2010.

NUNES, Klivia de Cassia Silva. Cenário da educação do campo estado do Tocantins. In: ii seminário nacional de estudos e pesquisas sobre educação do campo e vi jornada de educação especial no campo, 2013, São Carlos. II seminário nacional de estudos e pesquisas sobre educação do campo e vi jornada de educação especial no campo. São Carlos: UFSCar, 2013. v. 1. p. 1-14
REIS, N.S. Políticas educacionais do campo: percurso preliminar. Revista HISTEDBR On-line, Campinas, número especial, p. 124-148, out2011 ISSN: 1676-2584. Disponível em http://www.histedbr.fe.unicamp.br/revista/edicoes/43 e/art07_43e.pdf. Acesso em 11 de agosto de 2015

SILVA J. A. F. ; NETTO, M. B. . Por uma Educação do Campo: percursos históricos e possibilidades. Entrelaçando: Revista Eletrônica de Culturas e Educação, v. 1, p. 45-60, 2011.

SCHULTZ, E. A. D. ; LIRA, E. R. . Educação e Desenvolvimento no Estado do Tocantins: uma realidade possível? Campo - Território, v. 6, p. 104-133, 2011.

SOUZA, Maria Antônia. Educação do campo: políticas, práticas pedagógicas e produção científica. In: Educ. Soc., Campinas, vol. 29, n. 105, p. 1089-1111, set./dez. 2008. Disponível em http://www.cedes.unicamp.br Acesso em $11 \mathrm{de}$ março de 2015. 